\title{
Promoting Student Engagement and Preparation in Flipped Learning's Pre-Class Activities - A Systematic Review
}

\author{
Jessica Yang Shan Mei \\ Ngee Ann Polytechnic
}

Flipped learning is an instructional model with core features of pre-class learning followed by in-class practice of knowledge through active and collaborative learning. However, non-compliance with pre-class activities is a commonly cited challenge in flipped learning, where a lack of student engagement leads to insufficient pre-class preparation, diminishing flipped learning's intended benefits significantly as the students will then not participate well in the in-class activities. It lends consideration to the potential obstacles and solutions in increasing students' engagement in pre-class learning, paving the way to preclass learning compliance to achieve the full potential of flipped learning in improving students' learning outcomes. This study uses systematic literature review with qualitative content analysis to identify three main areas, namely technological, pedagogical, and student perceptions, to instill optimal conditions to promote pre-class engagement and preparation.

Keywords: flipped learning, pre-class learning, student engagement, preparation, systematic literature review, technological, pedagogical, student perceptions

\section{INTRODUCTION}

Flipped learning (FL) is an instructional model with core features of pre-class learning followed by inclass practice of knowledge through active and collaborative learning. The student-centered learning strategies allow the students to partake in higher-order thinking activities, leading to deeper understanding of the subject content. Pre-class and in-class components are indispensable complements of FL, and yet the general consensus in literature points to the in-class learning as a more critical component of FL (Bergmann \& Sams, 2014), placing a stronger emphasis on FL theories supporting the in-class element (Lee, Lim, \& Kim, 2017). This contradicts-recent research findings of the strong correlation of pre-class learning to final learning outcomes, nearly twice of that in comparison to in-class learning, and the success in using FL hinges on pre-class learning much more significantly than what is commonly suggested in literature (Lee \& Choi, 2019). It leverages on the findings that pre-class learning is an important phase for learners to prepare for upcoming in-class activities, where it levels lower-performing students to a common ground of knowledge with the higher-performing ones, such that all students can participate equally in the in-class collaborative learning activities (Jong, 2017). However, this is challenged by the tendency of students to neglect pre-class learning, turning up for the in-class segment unprepared and unable to contribute meaningfully in the collaborative activities (W. He, Holton, Farkas, \& Warschauer, 2016). It has a negative impact for both themselves and the well-prepared students, with repercussions more far-fetching than the in-class activities alone, negatively affecting motivation, academic performance, and students' perceptions 
towards the FL model (W. He et al., 2016). Habitual resistance was also flagged as one of the main reasons for non-compliance, due to the perception that FL increases workload on the students' part with the preclass learning (W. He et al., 2016), which can be further intensified through the non-participation in the inclass learning that causes the non-achievement of learning outcomes. There is also a paucity of literature employing qualitative methodologies to provide more in-depth understanding of FL, and a gap in understanding on contextualizing conceptual frameworks to support the assimilation of pre-class learning to the in-class segment for coherent linkage (Karabulut-Ilgu, Jaramillo Cherrez, \& Jahren, 2018; O'Flaherty \& Phillips, 2015).

With the aforementioned importance to ensure students complete pre-class learning successfully, and the literature gaps pertaining to this aspect, a systematic literature review was carried out on empirical and theoretical research to address the research question: What conditions promote student engagement and preparation in FL's pre-class activities? Sufficient pre-class preparation can then translate to effective implementation of FL, to inculcate higher-order thinking skills in students and a deeper understanding on the subject matter.

\section{METHOD}

A systematic review approach was adopted to address the research question, and qualitative content analysis was applied in analyzing the extracted data. A search was conducted on seven online databases, namely Directory of Open Access Journals, Education Research Complete, ERIC, IEEE Xplore Digital Library, Science Citation Index, ScienceDirect, and Social Sciences Citation Index, to search for relevant literature from their inception till March 2020 and limited to English, full text, and peer-reviewed journal articles. The search contained the search terms "flipped learning", "flipped classroom", "flipped instruction", "higher education", and "pre-class". No methodological search filters were applied which would otherwise limit the articles to specific study designs. This generated a total of 44 articles. The next phase of the review included reading the abstract of each of the 44 articles for relevance to the research question. In the process, the inclusion and exclusion criteria, as shown in Table 1, were being applied in the review of the abstracts.

TABLE 1

INCLUSION AND EXCLUSION CRITERIA

\begin{tabular}{|l|l|l|}
\hline Type of criterion & Inclusion criteria & Exclusion criteria \\
\hline Type of publication & Peer reviewed journal articles & Non-peer reviewed journal articles \\
\hline Sample & Higher education students & Pre-tertiary students \\
\hline Research methods & Qualitative & \\
\cline { 2 - 2 } & Quantitative & \\
\cline { 2 - 2 } & Mix methods & \\
\hline Publication period & Inception till Mar 2020 & Non-English \\
\hline Language & English & \multicolumn{2}{|c|}{} \\
\hline
\end{tabular}

Articles with minimal focus on the pre-class segment and mainly on in-class learning were discarded. As such, 13 articles were discarded from the review of the abstracts. Full-text papers were obtained for the remaining 31 articles, and they were read to review the articles' eligibility. 11 articles were discarded in this process. Eventually, 20 articles were selected for the systematic literature review, with a publication date of 2015-2020, and they were further verified to align with the inclusion and exclusion criteria. The selection process for these articles is represented in Figure 1. Based on the conventional approach for qualitative content analysis as proposed by Hsieh and Shannon (2005), relevant text in the selected articles that captured key concepts or thoughts were extracted and highlighted to derive codes. This led to the 
emergence of labels for codes that represented more than one key concept or thought, which were then organized into different categories and sub-categories based on their relationships.

\section{FIGURE 1 \\ ARTICLE SELECTION FLOWCHART ADAPTED FROM PRISMA}
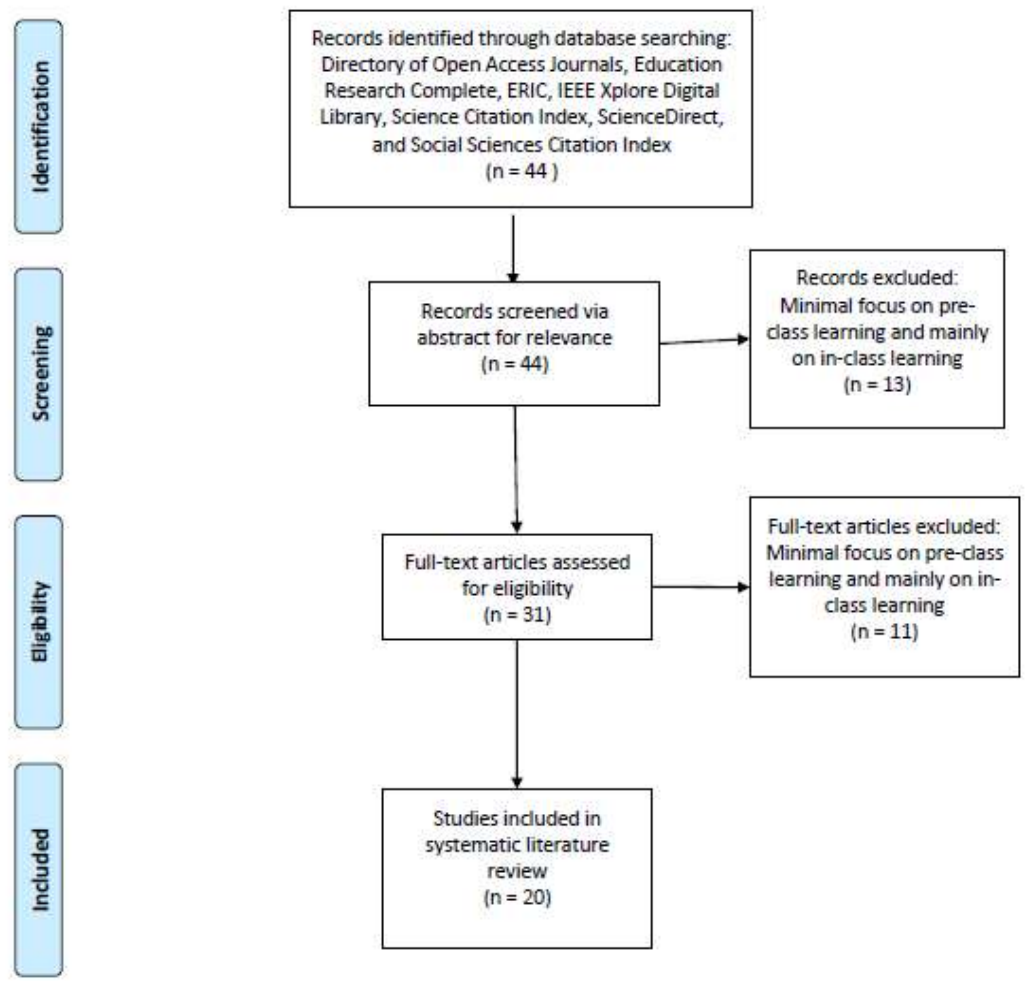

\section{DATA ANALYSIS}

20 articles were reviewed, with a mixture of qualitative, quantitative, and mixed methods research. The systematic literature review conducted in this study incorporated the learning experiences, academic performances, and perspectives from students in university education, except for one qualitative research that focused on a large-scale systematic review which included higher education apart from university. After applying qualitative content analysis to analyse the data from above 20 articles, three main categories and seven sub-categories emerged from the analysis, as represented in Table 2.

\section{TABLE 2 \\ CONDITIONS TO PROMOTE STUDENT ENGAGEMENT AND PREPARATION IN PRE-CLASS ACTIVITIES - CATEGORIES AND SUB-CATEGORIES}

\begin{tabular}{|c|c|c|c|}
\hline Categories & Technological & Pedagogical & \multirow{5}{*}{ Student Perceptions } \\
\hline \multirow[t]{4}{*}{ Sub-categories } & $\begin{array}{l}\text { Video resources' quality } \\
\text { and duration }\end{array}$ & Clarity of guidelines & \\
\hline & Technology accessibility & $\begin{array}{l}\text { Availability of immediate } \\
\text { feedback and support }\end{array}$ & \\
\hline & \multirow[t]{2}{*}{ Design of learning system } & Incentives for learning & \\
\hline & & Conceptual frameworks & \\
\hline
\end{tabular}




\section{Technological}

\section{Video Resources' Quality and Duration}

Ramnanan and Pound (2017) found that when multiple resources are provided for pre-class preparation, students access videos materials most frequently and express high levels of satisfactions for online videos. This is in agreement with findings that suggest pre-class videos are more preferred by students as compared to reading materials, thus more effective for students' pre-class learning and driving a clear advantage for students' performance in final summative assessments (Goedhart, Blignaut-van Westrhenen, Moser, \& Zweekhorst, 2019; Jensen et al., 2018). Instructor-developed videos were more preferred by the students than videos from alternative sources or guest speakers (Long, Logan, \& Waugh, 2016). The importance of communication in the videos is further highlighted through the positive findings that human presence has on students' learning, by increasing students' comprehension of its content through social cues in the videos that direct attention to important information (Ha, O'Reilly, Ng, Zhang, \& Serpa, 2019; Jensen et al., 2018). Students appreciate concise and professionally made video resources within a duration of 20-30 minute, with the learning content appropriately paced against a backdrop of high quality images, audio, and text (Long et al., 2016). The findings also suggest that the videos' length should be within 15-20 minute, to capture majority of students' attention span (Akçayır \& Akçayır, 2018; Lee \& Choi, 2019; Xiu, Moore, Thompson, \& French, 2019).

\section{Technology Accessibility}

Accessibility of the online materials is strongly correlated to students' satisfaction in pre-class learning (Ramnanan \& Pound, 2017), which is related to the findings on students' perception of convenience when they can access the online resources at their preferred time and place resulting in improved study quality and pre-class preparation (Goedhart et al., 2019). Internet connectivity is essential to ensure this accessibility, and thus ensuring that students are aware of the possible technical issues and the relevant solutions can help to greatly reduce students' frustration, and promote engagement with the materials (Karabulut-Ilgu et al., 2018). Gündüz and Akkoyunlu (2019) recommended copies of pre-class online materials saved in digital versatile discs (DVDs) as back-up for students' access, should their technical issues remained unresolved. Since the technology accessibility of the online materials play a pivotal role in students' engagement with online materials, the technology availability of students and their digital competencies have to be examined before designing the pre-class learning in FL, for alignment with students' needs to reduce frustration and promote engagement (Akçayır \& Akçayır, 2018).

\section{Design of Learning System}

The findings suggest that the learning system's design, where the online resources are hosted, plays a role in promoting students' learning engagement. Dooley et al. (2018) discovered that students valued a structured online system which allowed for ease of navigation to access relevant parts of the pre-class content, and pass over non-essential sections. In addition, it is suggested in the findings that a learning system that can generate warnings to learners, especially for those with a tendency to neglect the pre-class learning, will also help to improve the state of preparedness for the pre-class activities (Lee \& Choi, 2019).

\section{Pedagogical}

Clarity of Guidelines

Proper guidance to pre-class preparation should be provided by instructors to avert inefficient or unproductive learning, and this is found to be particularly important for students with low metacognition level (Shibukawa \& Taguchi, 2019). Guidance includes clear demonstration of pre-class activities in a timeeffective manner during the first lesson, and presenting the learning objectives' meaning as well as the recommended methods to achieve them (Ha et al., 2019; Shibukawa \& Taguchi, 2019). In addition, explaining the rationale and advantages of applying FL in achieving the learning objectives from the beginning, as well as the importance of pre-class learning in FL's design, will help to motivate students to complete their pre-class preparation particularly for those with low self-directedness (Ha et al., 2019; Lee \& Choi, 2019; Xiu et al., 2019). 


\section{Availability of Immediate Feedback and Support}

Students value a highly structured online platform where learning is not only navigated easily, but with provision of early formative feedback for individualized learning adapted to personal needs (Dooley et al., 2018). The feedback may be added at the end of video resources, which can better scaffold students' understanding of the content, and allows for self-assessment of learning progress to moderate study methods for improved learning outcomes (Das et al., 2019; Dooley et al., 2018; Xiu et al., 2019). In addition to a structured learning platform and formative feedback, a communication channel is also necessary for students' interaction with the instructors to obtain feedback and assistance should they have questions, to better support their pre-class learning conducted outside of the classroom (Akçayır \& Akçayır, 2018; Gündüz \& Akkoyunlu, 2019).

\section{Incentives for Learning}

The findings suggest that students should be provided with incentives to encourage compliance with pre-class preparation, which can be given through the form of low-stakes quizzes or assignments on the video content (W. He, Holton, Gu, Warschauer, \& Farkas, 2019). Xiu et al. (2019) found that a five minute duration quiz was well-received by students. However, the quizzes should still help the students to check on their understanding of key concepts, and sufficient time for completion and marks albeit low-stakes should be planned for the quizzes to motivate students in fulfilling them (Ha et al., 2019; W. He et al., 2019; Xiu et al., 2019).

\section{Conceptual Frameworks}

It is important for instructors to provide scaffolding for students to learn strategies for planning, monitoring, and reflecting on their pre-class learning to achieve academic success in the FL model (Zheng, Ward, \& Stanulis, 2020). This is in agreement with the study from Yilmaz \& Baydas (2017), that metacognition strategies can be incorporated in the pre-class activities to better engage the students, and help them to effectively plan, monitor, and evaluate their learning progress. Metacognitive strategies are methods to define the mental activities used in evaluating own thinking processes or strategies in the course of learning, helping students to evaluate and decide on the arrangements to improve the quality of learning process (Kaya, 2012).

Learning reflections and knowledge integration can also be better supported by designing the pre-class learning experience based on the conceptual framework, Knowledge Integration Theory ( $Z$. Wang, Yang, Chen, \& Long, 2019). The theory defines the process where learners can build understanding through adding, sorting, evaluating, distinguishing, and refining ideas from learning, to transform fragmented knowledge into coherent thoughts (Chiu \& Linn, 2011). Z. Wang et al. (2019) found that Knowledge Integration Theory had a positive effect on students' self-efficacy in completing tasks required for pre-class learning. This helps to construct a coherent understanding between new and old knowledge that forms the connection between pre-class and in-class learning, in which the connection is deemed to be crucial in improving the engagement in pre-class learning (Goedhart et al., 2019).

\section{Students' Perceptions}

The design of the pre-class learning should take into account the sustainability and efficiency of the students' preparation, which helps the students to be more accepting of the FL environment and improve their engagement in the pre-class activities (McNally et al., 2017; Shibukawa \& Taguchi, 2019). In general the more demanding the pre-class preparation, the less preference the students demonstrate towards the tasks involved, which decreases their engagement (McNally et al., 2017). Communication to the students should be done at the start of the FL to dispel concerns that the instructional model is increasing the amount of study time needed, but instead it is merely a shift in the workload distribution (W. He et al., 2019). This diminishes the resistance students have towards FL, which is important as it helps them to have better selfregulation in learning and a higher degree of responsibility to fulfill the pre-class preparation, which they may not be accustomed to as it may deviate from previous schooling experience (Nanclares \& Rodríguez, 2016). 


\section{DISCUSSION}

There are several conditions that can help to promote student engagement and preparation in pre-class learning activities, as found in this systematic literature review. Videos are the most commonly employed resources for learning outside of the classroom, as they are easier to comprehend than their text-based counterparts (Diwanji et al., 2014; Y. He, Swenson, \& Lents, 2012; Kay \& Kletskin, 2012). Coupled with internet connectivity, online videos are appreciated by the students for the convenience in learning at selected time and pace, which is a key advantage of pre-class learning and a main reason for students' satisfaction with FL (Nguyen et al., 2016; O'Flaherty \& Phillips, 2015). The findings in the review further extend to the design of formative feedback mechanisms to support individualized learning, and a consideration on possible online platforms to incorporate videos with low-stake quizzes to promote engagement and preparation in pre-class learning. This brings an understanding on the benefits of incentivizing learning, and also the consideration on promoting student engagement by assessing the full pre-class learning component if marks motivate the students in completion. Yet on the other hand, there is the concern that students may complete the quizzes only for the sake of marks acquisition rather than learning, which may then backfire on engagement through the potential action of skimming resources for possible answers (Gardner et al., 2014). The improvement of students' engagement with lecturer's presence in the video are in agreement with other studies showing positive influences on students' perceived learning and satisfaction, though it is suggested that this presence be used strategically to avoid distraction of students' attention when presenting challenging information (J. Wang \& Antonenko, 2017). Learning platforms with easy navigation and systems in place to remind students of uncompleted tasks should be also prioritized. On the institutional-front, this implies that more reinforcement and resources should be delegated to developing academic staff's digital competencies, especially with FL being a commonly employed instructional model globally (Hao, 2016). More digital tools in video recording should be made accessible in the institutions, to allow instructors the flexibility in choosing relevant tools to align with personal digital competencies and students' preference for creating the resources. Likewise for hosting resources on online platforms, widening the variety of choices allows instructors the consideration of suitable platforms to design ease of navigation within the learning, and align with students' digital competencies to reduce students' frustration in interacting with technology. With resources hosted online for pre-class learning, it is also crucial to ensure technology accessibility for all students, which correlates to students' learning satisfaction from the findings. It is suggested to prepare solutions to possible technical errors, as well as backup hard copies of resources to enhance the accessibility aspect for the students. The importance of technology accessibility implies that institutions implementing FL should also examine the technology availability for all students, and provide digital devices and access to internet connectivity when necessary, to allow all students to access online learning (van Rooij \& Zirkle, 2016).

The review has suggested conditions in the pedagogical aspect, such as clarity of guidelines with timeeffective learning strategies, proper explanation of learning objectives and the importance of pre-class learning to better engage students. This is especially beneficial for students with low metacognition and self-directedness, who have a tendency to exhibit non-compliance in pre-class preparation (Chen, Wang, \& Chen, 2014). From the findings, the contextualization of conceptual framework Knowledge Integration Theory in pre-class learning design can help the students to construct better connection with in-class learning, so that students are more motivated to prepare for class (O'Flaherty \& Phillips, 2015; Tucker, 2012). In addition, metacognitive strategies can also allow students to plan, monitor, and evaluate their learning progress for better engagement. This implies that institutions have to plan for academic staff development to use these pedagogical frameworks effectively within FL's design. The development also extends to other aspects such as designing enough time and sustainability in FL, for students to perform their required pre-class learning assisted with clear guidelines. It is possible to fall back on the findings which suggest a guideline for resources to be conducted within a 15-30 minute period to capture students' attention (Lee \& Choi, 2019; Long et al., 2016; Xiu et al., 2019; Zheng et al., 2020), to decide on a sustainable timeframe for the pre-class learning. On the other side of the consideration, the adaptability of the pre-class learning design within a specified timeframe may be well subjected to its feasibility with 
regards to the intended learning objectives. As such, whether all designs should cater to a pre-determined timeframe, or should priority be given to establishing a suitable duration to achieve the learning objectives, with intentional development to stretch students' resilience and attention span is food for thought.

\section{TABLE 3 \\ RECOMMENDATIONS TO PROMOTE STUDENT ENGAGEMENT AND PREPARATION IN PRE-CLASS ACTIVITIES}

\begin{tabular}{|ll|}
\hline 1. & $\begin{array}{l}\text { Design pre-class learning in a timeframe of } 15-30 \text { minute, aligned with students' technology } \\
\text { availability and digital competencies. }\end{array}$ \\
\hline 2. & $\begin{array}{l}\text { Contextualize Knowledge Integration Theory and metacognitive strategies in pre-class learning } \\
\text { design. }\end{array}$ \\
\hline 3. & Use online videos with lecturer's presence, high quality images, audio, and text. \\
\hline 4. & Incorporate low-stake quizzes with formative feedback. \\
\hline 5. & $\begin{array}{l}\text { Host pre-class learning on learning systems with easy navigation and reminders for uncompleted } \\
\text { tasks. }\end{array}$ \\
\hline 6. & Create troubleshooting guides for potential technical errors, and backup hard copies of materials. \\
\hline 7. & Provide digital devices and internet connectivity to level technology accessibility. \\
\hline 8. & $\begin{array}{l}\text { Create clear guidelines with time-effective learning strategies, explanation of learning objectives } \\
\text { and importance of pre-class learning. }\end{array}$ \\
\hline 9. & Assure students FL does not create an increase in study load, but a shift in study load distribution. \\
\hline 10. & Provide a communication channel for students to obtain assistance and feedback from lecturers. \\
\hline
\end{tabular}

\section{CONCLUSION}

The use of systematic literature review with qualitative content analysis has addressed the research question by identifying the conditions to promote student engagement and preparation in FL's pre-class activities. The review has allowed insights into the circumstances that impede engagement with pre-class learning, be it psychological or physical, leading to insufficient preparation which may potentially set the FL instructional model for failure. Consolidation of the findings in response to these possible circumstances has led to the identification of three main areas to focus on in instilling optimal conditions to promote preclass engagement and preparation, namely technological, pedagogical, and student perceptions. The importance of pre-class preparation is especially highlighted through the contradictory findings of students' key satisfaction in the model due to the convenience and flexibility of online pre-class activities, yet afflicted by a common problem of non-compliance in this segment that degrades the benefits of FL. Considering that strategic design of pre-class learning is key to ensure the success of FL, practitioners have frequently neglected this aspect as found by Lee and Choi (2019). It is thus hopeful that through the contributions in this review, educators can better understand the pre-class learning's importance and utilize the findings to further evaluate and develop the design in this area, for improved students' engagement and preparation to reap the advantages of FL.

Exclusion of articles on pre-tertiary education increases data homogeneity of findings in higher education, however valuable insights might have been missed out. Furthermore, the articles reviewed have a major emphasis on university education, with only one article offering perspectives in other areas of higher education. The singular focus on one particular education genre may lead to the influence of the findings by a certain student demographic, which can limit its generalization beyond university education. Further investigations can compile findings across the spectrum of education, from pre-tertiary education to higher education, so that the insights can be more diversified, improving the generalization of findings that benefits educators from different backgrounds. Investigation on strategies fostering positive students' perceptions towards pre-class learning can also be included in future studies. 


\section{REFERENCES}

Abeysekera, L., \& Dawson, P. (2015). Motivation and cognitive load in the flipped classroom: Definition, rationale, and a call for research. Higher Education Research \& Development, 34(1), $1-14$.

Adom, D., Yeboah, A., \& Ankrah, A. (2016). Constructivism philosophical paradigm: Implication for research, teaching and learning. Global Journal of Arts Humanities and Social Sciences, 4(10), 19.

Akçayır, G., \& Akçayır, M. (2018). The flipped classroom: A review of its advantages and challenges. Computers \& Education, 126, 334-345. doi:10.1016/j.compedu.2018.07.021

Al-Zahrani, A.M. (2015). From passive to active: The impact of the flipped classroom through social learning platforms on higher education students' creative thinking. British Journal of Educational Technology, 46(6), 1133-1148.

Bearman, M., \& Dawson, P. (2013). Qualitative synthesis and systematic review in health professions education. Medical Education, 47(3), 252-260.

Bengtsson, M. (2016). How to plan and perform a qualitative study using content analysis. Nursing Plus Open, 2, 8-14.

Bergmann, J., \& Sams, A. (2012). Flip your classroom: Reach every student in every class every day. International Society for Technology in Education.

Bergmann, J., \& Sams, A. (2014). Flipped learning: Gateway to student engagement. International Society for Technology in Education.

Betihavas, V., Bridgman, H., Kornhaber, R., \& Cross, M. (2016). The evidence for flipping out: A systematic review of the flipped classroom in nursing education. Nurse Education Today, 38, 1521.

Chen, Y., Wang, Y., \& Chen, N-S. (2014). Is flip enough? Or should we use the flipped model instead? Computers \& Education, 79, 16-27.

Chiu, J.L., \& Linn, M.C. (2011). Knowledge integration and wise engineering. Journal of Pre-College Engineering Education Research, 1(1), 2-14.

Das, A., Lam, T.K., Thomas, S., Richardson, J., Kam, B.H., Lau, K.H., \& Nkhoma, M.Z. (2019). Flipped classroom pedagogy: Using pre-class videos in an undergraduate Business Information Systems Management course. Education \& Training, 61(6), 756-774.

Diwanji, P., Simon, B.P., Märki, M., Korkut, S., \& Dornberger, R. (2014). Success factors of online learning videos. Paper presented at the 2014 International Conference on Interactive Mobile Communication Technologies and Learning (IMCL2014).

Dooley, L.M., Frankland, S., Boller, E., \& Tudor, E. (2018). Implementing the flipped classroom in a veterinary pre-clinical science course: Student engagement, performance, and satisfaction. Journal of Veterinary Medical Education, 45(2), 195-203.

Elo, S., Kääriäinen, M., Kanste, O., Pölkki, T., Utriainen, K., \& Kyngäs, H. (2014). Qualitative content analysis: A focus on trustworthiness. SAGE Open, 4(1), 2-10.

Gardner, A., Willey, K., Vessalas, K., \& Li, J. (2014). Experiences with flipped learning in subjects in consecutive stages of a Civil Engineering programme. Paper presented at the AAEE-Annual Conference of Australasian Association for Engineering Education.

Goedhart, N., Blignaut-van Westrhenen, N., Moser, C., \& Zweekhorst, M. (2019). The flipped classroom: Supporting a diverse group of students in their learning. Learning Environments Research, 22(2), 297-310.

González-Gómez, D., Jeong, J.S., \& Rodríguez, D.A. (2016). Performance and perception in the flipped learning model: An initial approach to evaluate the effectiveness of a new teaching methodology in a general science classroom. Journal of Science Education and Technology, 25(3), 450-459.

Gündüz, A.Y., \& Akkoyunlu, B. (2019). Student views on the use of flipped learning in higher education: A pilot study. Education and Information Technologies, 24(4), 2391-2401. 
Ha, A.S., O’Reilly, J., Ng, J.Y., Zhang, J.H., \& Serpa, S. (2019). Evaluating the flipped classroom approach in Asian higher education: Perspectives from students and teachers. Cogent Education, 6(1), 1-12.

Hao, Y. (2016). Exploring undergraduates' perspectives and flipped learning readiness in their flipped classrooms. Computers in Human Behavior, 59, 82-92.

He, W., Holton, A., Farkas, G., \& Warschauer, M. (2016). The effects of flipped instruction on out-ofclass study time, exam performance, and student perceptions. Learning and Instruction, 45, 6171.

He, W., Holton, A., Gu, H., Warschauer, M., \& Farkas, G. (2019). Differentiated impact of flipped instruction: When would flipped instruction work or falter? International Journal of Teaching and Learning in Higher Education, 31(1), 32-49.

He, Y., Swenson, S., \& Lents, N. (2012). Online video tutorials increase learning of difficult concepts in an undergraduate analytical chemistry course. Journal of Chemical Education, 89(9), 1128-1132.

Hsieh, H-F., \& Shannon, S.E. (2005). Three approaches to qualitative content analysis. Qualitative Health Research, 15(9), 1277-1288.

Jacobson, W. (1998). Defining the quality of practitioner research. Adult Education Quarterly, 48(3), $125-138$.

Jahan, N., Naveed, S., Zeshan, M., \& Tahir, M.A. (2016). How to conduct a systematic review: A narrative literature review. Cureus, 8(11), 864-883.

Jensen, J.L., Holt, E.A., Sowards, J.B., Ogden, T.H., \& West, R.E. (2018). Investigating strategies for pre-class content learning in a flipped classroom. Journal of Science Education and Technology, 27(6), 523-535.

Jesson, J., Jesson, J.K., Matheson, L., \& Lacey, F. (2011). Doing your literature review: Traditional and systematic techniques. Sage.

Jong, M.S-Y. (2017). Empowering students in the process of social inquiry learning through flipping the classroom. Journal of Educational Technology \& Society, 20(1), 306-322.

Jordan, S. (2012). Student engagement with assessment and feedback: Some lessons from short-answer free-text e-assessment questions. Computers \& Education, 58(2), 818-834.

Kahu, E.R. (2013). Framing student engagement in higher education. Studies in Higher Education, 38(5), 758-773.

Karabulut-Ilgu, A., Jaramillo Cherrez, N., \& Jahren, C.T. (2018). A systematic review of research on the flipped learning method in engineering education. British Journal of Educational Technology, 49(3), 398-411.

Kay, R., \& Kletskin, I. (2012). Evaluating the use of problem-based video podcasts to teach Mathematics in higher education. Computers \& Education, 59(2), 619-627.

Kaya, S. (2012). The effects of cognitive and metacognitive strategy activities on pre-service teachers' achievements in Instructional Design course and their levels of cognitive and metacognitive strategy usage. (Unpublished Doctor of Philosophy thesis). Gazi University, Ankara.

Khanova, J., Roth, M.T., Rodgers, J.E., \& McLaughlin, J.E. (2015). Student experiences across multiple flipped courses in a single curriculum. Medical Education, 49(10), 1038-1048.

Kivunja, C., \& Kuyini, A.B. (2017). Understanding and applying research paradigms in educational contexts. International Journal of Higher Education, 6(5), 26-41.

Lai, C-L., \& Hwang, G-J. (2016). A self-regulated flipped classroom approach to improving students' learning performance in a Mathematics course. Computers \& Education, 100, 126-140.

Lee, J., \& Choi, H. (2019). Rethinking the flipped learning pre-class: Its influence on the success of flipped learning and related factors. British Journal of Educational Technology, 50(2), 934-945.

Lee, J., Lim, C., \& Kim, H. (2017). Development of an instructional design model for flipped learning in higher education. Educational Technology Research and Development, 65(2), 427-453.

Long, T., Logan, J., \& Waugh, M. (2016). Students' perceptions of the value of using videos as a preclass learning experience in the flipped classroom. TechTrends, 60(3), 245-252. 
Masland, L., \& Gizdarska, S. (2018). "Then what am I paying you for?" Student attitudes regarding preclass activities for the flipped classroom. International Journal of Teaching and Learning in Higher Education, 30(2), 234-244.

McDonald, K., \& Smith, C.M. (2013). The flipped classroom for professional development: Benefits and strategies. The Journal of Continuing Education in Nursing, 44(10), 437-438.

McNally, B., Chipperfield, J., Dorsett, P., Del Fabbro, L., Frommolt, V., Goetz, S., . . Rung, A. (2017). Flipped classroom experiences: Student preferences and flip strategy in a higher education context. Higher Education, 73(2), 281-298.

Nanclares, N.H., \& Rodríguez, M.P. (2016). Students' satisfaction with a blended instructional design: The potential of flipped classroom in higher education. Journal of Interactive Media in Education, (1), 1-12.

Nguyen, B., Yu, X., Japutra, A., \& Chen, C.H.S. (2016). Reverse teaching: Exploring student perceptions of flip teaching. Active Learning in Higher Education, 17(1), 51-61.

O'Flaherty, J., \& Phillips, C. (2015). The use of flipped classrooms in higher education: A scoping review. The Internet and Higher Education, 25, 85-95.

Ramnanan, C.J., \& Pound, L.D. (2017). Advances in medical education and practice: Student perceptions of the flipped classroom. Advances in Medical Education and Practice, 8, 63-73.

Roehl, A., Reddy, S.L., \& Shannon, G.J. (2013). The flipped classroom: An opportunity to engage millennial students through active learning strategies. Journal of Family \& Consumer Sciences, 105(2), 44-49.

Ryan, M.D., \& Reid, S.A. (2016). Impact of the flipped classroom on student performance and retention: A parallel controlled study in general chemistry. Journal of Chemical Education, 93(1), 13-23

Sahin, A., Cavlazoglu, B., \& Zeytuncu, Y.E. (2015). Flipping a college calculus course: A case study. Journal of Educational Technology \& Society, 18(3), 142-152.

Sayeski, K.L., Hamilton-Jones, B., \& Oh, S. (2015). The efficacy of IRIS STAR legacy modules under different instructional conditions. Teacher Education and Special Education, 38(4), 291-305.

Shibukawa, S., \& Taguchi, M. (2019). Exploring the difficulty on students' preparation and the effective instruction in the flipped classroom. Journal of Computing in Higher Education, 31(2), 311-339.

Smith, J.D. (2013). Student attitudes toward flipping the general chemistry classroom. Chemistry Education Research and Practice, 14(4), 607-614.

Toney, R.J. (2000). An investigation of learner control and metacognition using a web-based training program. ProQuest Information \& Learning.

Tucker, B. (2012). The flipped classroom. Education Next, 12(1), 82-83.

van Rooij, S.W., \& Zirkle, K. (2016). Balancing pedagogy, student readiness and accessibility: A case study in collaborative online course development. The Internet and Higher Education, 28, 1-7.

Wang, J., \& Antonenko, P.D. (2017). Instructor presence in instructional video: Effects on visual attention, recall, and perceived learning. Computers in Human Behavior, 71, 79-89.

Wang, Z., Yang, X., Chen, L., \& Long, T. (2019). Designing pre-class learning experience based on the Knowledge Integration Theory: Investigating its effect on pre-service teachers' flipped classroom Learning. 2019 Eighth International Conference on Educational Innovation through Technology (EITT), pp. 120-125.

Winne, P.H. (2010). Improving measurements of self-regulated learning. Educational Psychologist, 45(4), 267-276.

Wright, R.W., Brand, R.A., Dunn, W., \& Spindler, K.P. (2007). How to write a systematic review. Clinical Orthopaedics and Related Research, 455, 23-29.

Xiu, Y., Moore, M.E., Thompson, P., \& French, D.P. (2019). Student perceptions of lecture-capture video to facilitate learning in a flipped classroom. TechTrends, 63(4), 369-375.

Zainuddin, Z., \& Halili, S.H. (2016). Flipped classroom research and trends from different fields of study. International Review of Research in Open and Distributed Learning, 17(3), 313-340.

Zheng, B., Ward, A., \& Stanulis, R. (2020). Self-regulated learning in a competency-based and flipped learning environment: Learning strategies across achievement levels and years. Medical Education Online, 25(1), 1-7. 